\title{
Eco-trench: a novel trench solution based on reusing excavated material and a finishing layer of expansive concrete
}

\author{
A. Blanco $\bowtie$, P. Pujadas, C. Fernández, S.H.P. Cavalaro, A. Aguado \\ Dept. of Civil and Environmental Engineering, Universitat Politècnica de Catalunya, (Barcelona, Spain) \\ \ana.blanco@upc.edu
}

\begin{abstract}
Installing utility pipelines generates a significant amount of trench arisings, which are usually transported to landfills instead of being reused as backfill material. This practice generates $\mathrm{CO}_{2}$ emissions and wastes raw materials. This paper presents a more sustainable solution, an eco-trench, which is based on re-using trench arisings as backfill and adding a top layer of expansive concrete to improve the eco-trench's structural performance. The technical feasibility of the eco-trench was evaluated through a finite element model, which identified the degree of expansion in concrete required to avoid failure or subside the stresses caused by traffic. The potential expansion of concrete was measured under confined conditions in the laboratory by means of a novel test developed for this purpose. The results showed that adding calcium oxide generates the required internal stress. The results were then confirmed in a pilot experience.
\end{abstract}

KEYWORDS: Concrete; Mixture proportion; Expansion; Finite element method; Shrinkage

Citation/Citar como: Blanco, A.; Pujadas, P.; Fernández, C.; Cavalaro, S.H.P.; Aguado, A. (2017) Eco-trench: a novel trench solution based on reusing excavated material and a finishing layer of expansive concrete. Mater. Construcc. 67 [328], e135. http://dx.doi.org/10.3989/mc.2017.05316

RESUMEN: Ecozanja: una nueva solución de zanja basada en la reutilización de material excavado y una capa de hormigón expansivo. Las zanjas para instalaciones de servicios generan un elevado volumen de materiales de excavación que son transportados a vertederos en lugar de ser reaprovechados como relleno. Esto conlleva un mayor consumo de materias primas y emisiones de $\mathrm{CO}_{2}$ asociadas al transporte. Este estudio presenta una solución más sostenible, denominada ecozanja, basada en la reutilización de los materiales de excavación como relleno de la zanja con una capa superficial de hormigón expansivo. Su aplicabilidad se evalúa mediante un modelo de elementos finitos que permite determinar el grado de expansión necesario en el hormigón para garantizar la resistencia de las tensiones debidas al tráfico de vehículos sobre la zanja. La expansividad del hormigón se evaluó mediante un ensayo desarrollado específicamente para tal objetivo. Los resultados indican que la adición de óxido de calcio genera las tensiones internas necesarias. Asimismo, la propuesta se validó mediante una experiencia piloto en obra.

PALABRAS CLAVE: Hormigón; Proporción de mezcla; Expansión; Método de elementos finitos; Retracción

ORCID ID: A. Blanco (http://orcid.org/0000-0003-4190-9846); P. Pujadas (http://orcid.org/0000-0001-5634-7431); C. Fernández (http://orcid.org/0000-0002-7106-5181); S. H. P. Cavalaro (http://orcid.org/0000-0002-9368-0898); A. Aguado (http://orcid.org/0000-0001-5542-6365)

Copyright: (C) 2017 CSIC. This is an open-access article distributed under the terms of the Creative Commons Attribution License (CC BY) Spain 3.0.

\section{INTRODUCTION}

Narrow trenches are dug when installing smalldiameter utility pipelines under pavement. After the original soil is extracted and the pipe is placed, these trenches are filled with granular material or a controlled low-strength mortar (1-3) that is intended to protect the pipe and give support to the pavement. In most cases, the residue, or trench arisings, obtained from the excavation is disposed of in landfills and 
new granular material is used as the backfill. This process wastes a considerable amount of raw material and transporting and disposing of the residue in landfills contributes to $\mathrm{CO}_{2}$ emissions (4). In light of this situation, the possibility of reusing the residue from the excavation should be analysed.

The idea of reusing trench arisings has already been considered in the UK, where 4.8 million tonnes of this material are generated per year (5) and several pilot experiences have been carried out (6). One of the conclusions of these experiences is that correctly identifying the materials in the trench arisings is essential. Consequently, not all excavated soils are suitable for reuse as backfill, which limits the range of materials that may be applied. Compaction is another fundamental factor that needs to be considered. The variability in soil characteristics in long stretches of construction affects the level of compaction needed to obtain filling that is capable of bearing the loads from the pavement. In practice, coping with this variation in compaction while also maintaining the construction schedule and reducing traffic interruptions becomes difficult.

Poorly selected soils or inadequate compaction may lead to problems during the service life of the trench, which include critical load concentrations on the pipe and pavement subsidence. In this context, the reuse of excavated soil is limited due to the difficulties related to proper selection and separation, as well as the risk of future problems. In order to overcome these drawbacks and promote the reuse of extracted soil, it is necessary to change the conventional philosophy behind the narrow trench system. The objective of this paper is to propose a new type of narrow trench system, which we call an eco-trench, that allows practically any soil to be reused as backfill without compromising the speed of the construction process or the performance of the pavement.

The proposed eco-trench system differs from a traditional system in that an expansive concrete finishing is applied to the top of the trench as pavement. This concrete contains an admixture that generates volumetric expansion during early ages (7-10). Given the properties of this kind of admixture, it has been commonly used to compensate for shrinkage. Nevertheless, in this case, not only is the volumetric expansion important, but also is the level of internal stresses generated when the concrete is confined. This may favour the transmission of stresses from traffic loads to the surrounding soil, which in turn would relieve the stresses on the backfill material and the pipe. Under such conditions, the restrictions on selecting the backfill are eliminated, making the reuse of the soil possible. Fig. 1 shows the cross-sections of a traditional trench and the proposed eco-trench.

In countries whose regulations governing road construction allow this type of solution to be adopted, there would be significant benefit. First, because the eco-trench solution does not require that the final layer of asphalt be added, there are advantages in execution, which entails an additional advantage in terms of execution (no overlaps are required), logistics and schedule.

Second, the number of asphalt production plants tends to be significantly lower than the amount of concrete plants. In the case of Spain, for example, according to ANEFHOP (the Spanish association of ready mix concrete) there are a total of 1,939 concrete plants, whereas the number of asphalt production plants is only a third of that. The scarcity of asphalt production plants creates a logistical problem in the worksite and higher costs. Furthermore, the use of a concrete layer favours reducing the amount $\mathrm{CO}_{2}$ in the environment since it reacts with portlandite during the carbonation process (11-12). This phenomenon is improved by adding calcium oxide to the concrete mix because more portlandite is generated.

The combination of reusing material as backfill and using expansive concrete as the final pavement is a potentially sustainable solution for narrow trench construction, and it should be technically assessed. To that end, finite element models were applied in order to evaluate the feasibility of the proposed
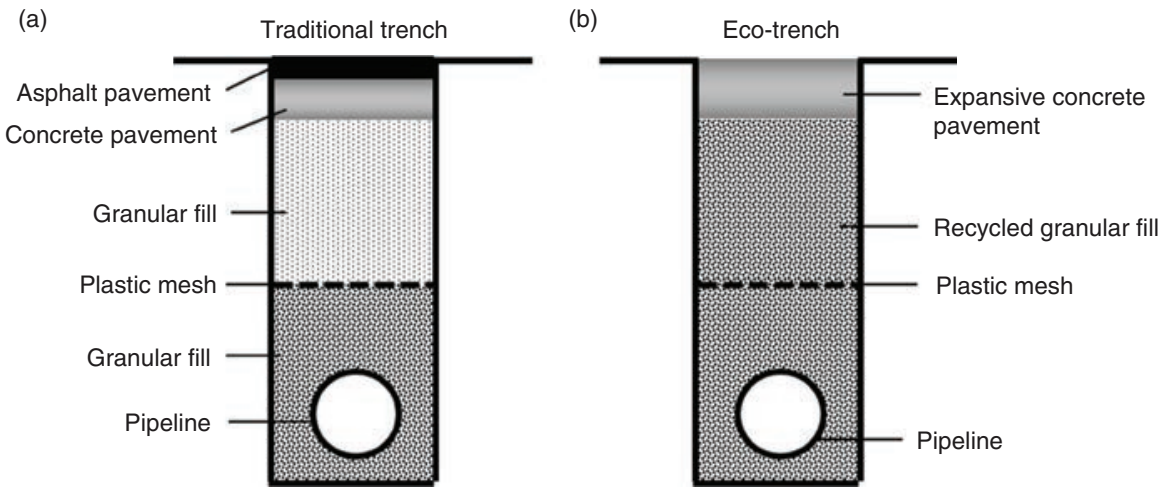

FIGURE 1. Cross-sections of: (a) traditional trench and (b) eco-trench. 
system, the interaction of the expansive concrete with the surroundings, and the level of confinement required. Then, an experimental program evaluated the stresses generated by concrete expansion using a new test method under confined conditions. Finally, a pilot experiment was run to evaluate the performance of the eco-trench under real work-site conditions. The new eco-trench solution is a step towards the sustainable trench construction and an example of new applications for expansive concrete.

\section{DESCRIPTION OF THE ECO-TRENCH}

The eco-trench is primarily conceived for narrow excavations (around $15 \mathrm{~cm}$ wide) with a depth of approximately $80 \mathrm{~cm}$. This type of trench is generally dug with automated equipment that grinds the original soil to a maximum size of $50 \mathrm{~mm}$ (depending on the type of soil, see Fig. 2). Traditionally, the maximum aggregate size recommended for the backfill used in narrow trenches is $6 \mathrm{~mm}$ in order to avoid differential settlement under the pipe or concentrated loads that might lead to punching its wall. However, given that an important part of the load is transmitted to the adjacent ground, in the case of eco-trenches a smaller load level should act on the pipe. Consequently, the restriction on maximum aggregate size may be relaxed depending on the type of pipe, and the material obtained from excavating can be reused. This assumption is valid as long as it is ensured that the minimum value of pre-compression applied to the adjacent ground is sufficient to avoid failure. In this case, pre-compression is provided by the internal stresses generated by the confined expansive concrete layer in the eco-trench.

After excavating the trench, a $5-\mathrm{cm}$ bed of fine soil is laid. The pipe is then placed on this bed and covered with a $20-\mathrm{cm}$ layer of fine material for protection. At this point, the utility companies usually place a plastic mesh in the trench to indicate the location of the pipe for future excavations (see Fig. 1). On top of the protective layer and the plastic mesh, a layer of excavated material that varies between $20 \mathrm{~cm}$ and $30 \mathrm{~cm}$ in thickness, depending on the total depth of the trench, is deposited. The final layer of the eco-trench consists of pigmented expansive concrete whose thickness may vary from $15 \mathrm{~cm}$ to $20 \mathrm{~cm}$. This layer of concrete should reach the street or road level without overlapping with the original pavement, and the visual aspects of the two should match. More details are provided about the properties of expansive concrete in subsequent sections.

\section{FAILURE MECHANISMS}

\subsection{Description of the types of failure}

The main actions to which the eco-trench is subjected during its service life are traffic loads. Depending on the location of the traffic load (or the wheel of the vehicle) relative to the trench, failure may be attributed to different mechanisms. Fig. 3 shows two cross-sections of an eco-trench subjected to traffic loads. In Fig. 3a, the loads are located in the width of the trench and overlap with the original pavement on one side, whereas in Fig. 3b the loads are evenly distributed at both sides of the trench.

In the first case, the traffic loads generate bending forces over the expansive concrete pavement and on the original pavement at one side of the eco-trench. These forces cause tensions at the opposite interface (the interface in contact with the pavement without traffic loads). If the pre-compression caused by the expansive concrete's internal stresses at the interface are lower than the tensions generated by the traffic loads, the trench could lose contact with the surrounding soil or pavement (see Fig. 3a). In the second case, since the traffic loads are symmetrically distributed in the cross-section, the failure of the eco-trench will not be in the form of a loss of contact. Instead, the critical parameter is the shear strength of the interface. If the tangential stresses generated by the traffic loads are higher than the
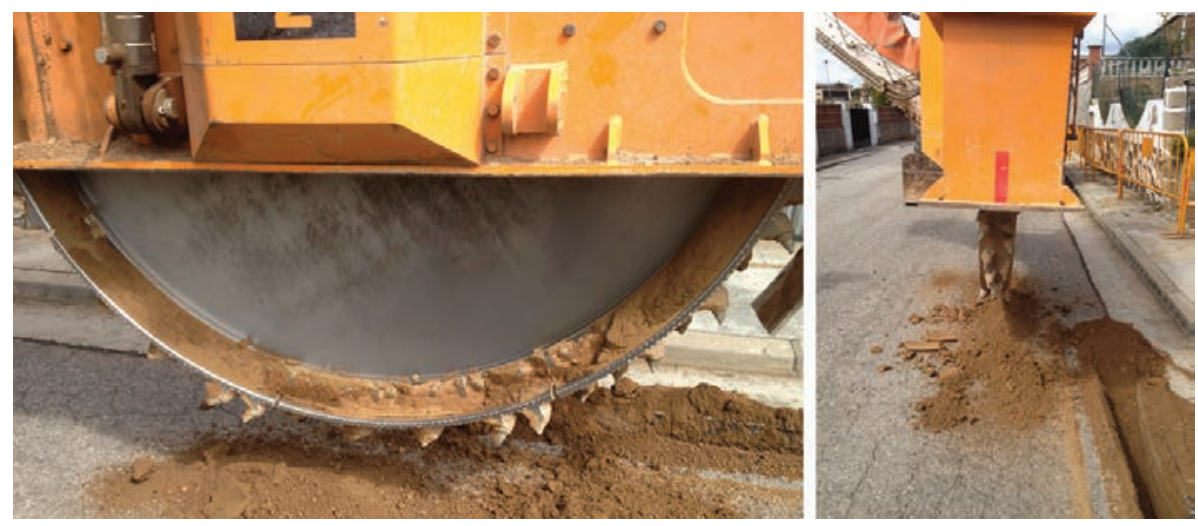

FIGURE 2. Excavation of a narrow trench and trench arisings. 
(a)

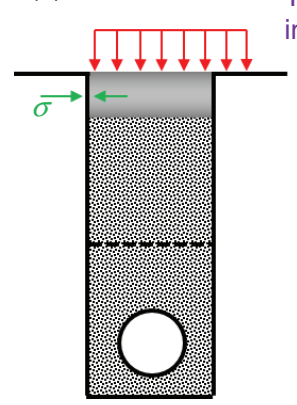

Tensile failure in the interface due to traffic loads

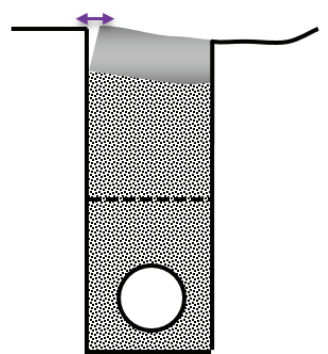

(b)

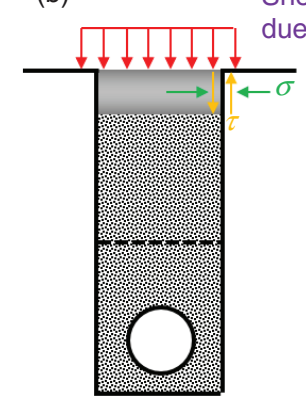

Shear failure in the interface due to traffic loads

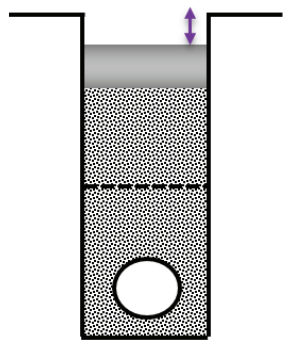

FIGURE 3. Failure modes of the eco-trench due to location of the traffic loads: (a) tension failure in the interface and (b) shear failure in the interface.

shear strength, a relative displacement could occur and the trench could subside.

To prevent the tensile failure shown in Fig. 3a, the internal stress generated by the expansive concrete should be equal to or higher than the limittension that generates the loss of contact. This is represented through Eq. [1], where $\sigma_{e}$ represents the internal stress due to the expansion of concrete and $\sigma_{n}$ is the normal limit-tension at which the loss of contact due to the traffic load occurs. Eq. [1] defines a minimum value of $\sigma_{e}$ in order to ensure that the stresses in the concrete are satisfactorily transmitted to the surrounding materials (pavement or soil), thus reducing the loads supported by the pipe.

$$
\sigma_{e} \geq \sigma_{n}
$$

A shear failure of the trench occurs when tangential stresses $(\tau)$ in the interface between the materials reach the shear strength of the interface and a relative displacement takes place (see Fig. 3b). According to the Mohr-Coulomb theory, tangential stresses resisted by the interface may be expressed as indicated in Eq. [2], where $\mu$ is the friction coefficient and $c$ is the cohesion.

$$
\tau \geq \sigma \cdot \mu+c
$$

Stress $\sigma$ in Eq. [2] may be decomposed in the normal limit-tension at which the loss of contact occurs due to the traffic load $\left(\sigma_{n}\right)$ and in the internal stress generated by the expansion process of the concrete $\left(\sigma_{e}\right)$, as indicated in Eq. [3]. As a result, the minimum value of $\sigma_{e}$ that ensures contact and avoids shear failure is obtained with Eq. [4], after organizing Eq. [3].

$$
\begin{gathered}
\tau \geq\left(\sigma_{n}+\sigma_{e}\right) \cdot \mu+c \\
\sigma_{e} \geq \frac{\tau-c}{\mu}-\sigma_{n}
\end{gathered}
$$

In order to determine the range of values for $\sigma_{e}$ that ensures the expansion required in the trench, a parametric study was carried out using finite element (FE) analysis, which is explained in the next section.

\section{NUMERICAL SIMULATION}

Numerical simulation was used to reproduce the behaviour of an eco-trench subjected to traffic loads and determine the minimum internal stress of the confined expansive concrete layer that is needed to transmit part of the load to the adjacent pavement and avoid failure. To that end, the two failure mechanisms previously described were analysed and the most restrictive one was identified. Based on this outcome, the limit values for the internal stress of the concrete were established.

\subsection{Description of the model}

Finite element software DIANA 9.1 (13) was chosen to simulate the behaviour of the trench due to its extensive material library and analysis capabilities. A 3D model was selected and the mesh was formed by four-node prismatic elements, which were refined for the area of the trench. Fig. 4 depicts the geometry of the model and the main types of elements that depend on the material properties. The geometry was defined by considering that the surrounding soil may present layers with different properties. The dimensions of the model corresponded to those typically found in practice. For the purpose of this study, asphalt with a thickness of $0.08 \mathrm{~m}$ was assumed in the top layer. Below that, two sub-base material (graded aggregate) layers were modelled. The top sub-base was $0.08 \mathrm{~m}$ thick and the bottom sub-base was $0.11 \mathrm{~m}$. The layers below the graded aggregate represent the original soil.

The narrow trench was evaluated for two widths: $0.15 \mathrm{~m}$ and $0.25 \mathrm{~m}$. The depth and the length of the trench, $1.27 \mathrm{~m}$ and $2.0 \mathrm{~m}$, respectively, remained constant in both cases. The top $0.15 \mathrm{~m}$ corresponded to the expansive concrete layer and the remaining 


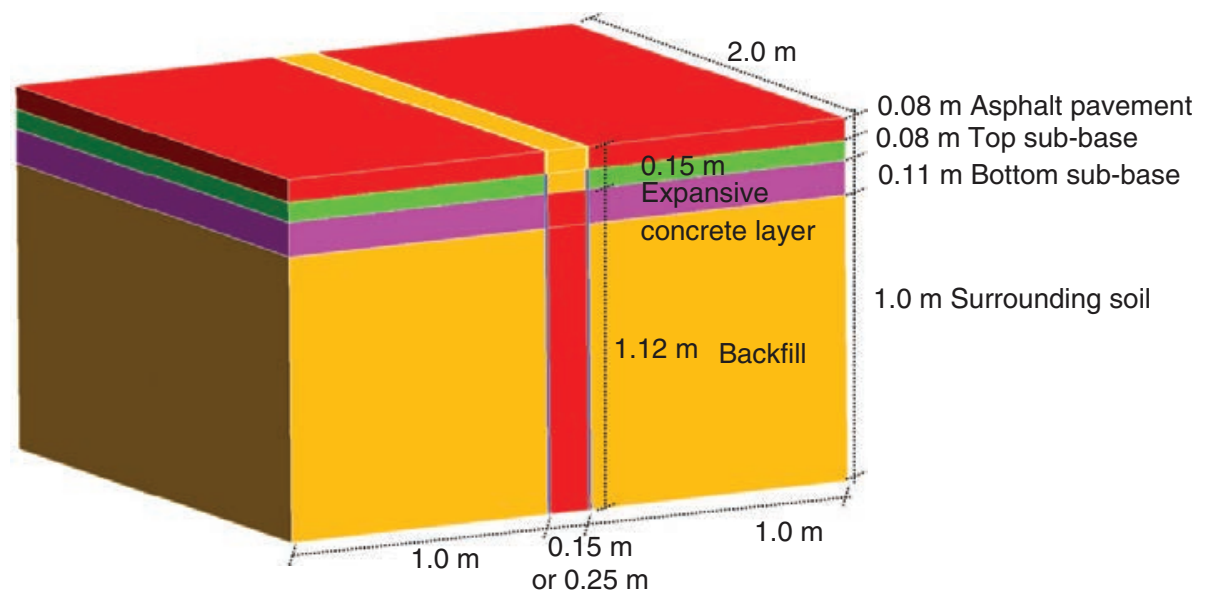

FIGURE 4. Geometry of the FE model.

$1.12 \mathrm{~m}$ were filled with reused granular material obtained from the excavation of the trench. The soil modelled at both sides of the trench was $1.0 \mathrm{~m}$ wide, so the complete model was $2.15 \mathrm{~m}$ wide (or $2.25 \mathrm{~m}$, depending on the width of the trench). The pipe was not included in the geometry of the model since it was assumed that the traffic loads in the eco-trench are borne by the expansive concrete layer and transmitted to the surrounding soil. For this reason, the model assumed that the pipe does not bear loads, which is the worst-case scenario in terms of expansion requirements for the concrete since it means that higher values of internal stress are required.

The boundary conditions set in the model corresponded to a spring support perpendicular to each plane of the model. The spring stiffness $(k)$ assumed was $10^{9} \mathrm{~N} / \mathrm{mm}^{3}$. Such a high value was defined to maximize the difference in stiffness and hence the shear stresses at the interface between the expansive concrete and the surrounding material. Failure was expected to occur at the interface between the expansive concrete and the surrounding pavement, which was modelled following a Coulomb friction model. Two types of contact between layers were defined in the model: perfect contact and weak contact. The stiffness values adopted in each case were $10^{10} \mathrm{~N} / \mathrm{m}^{3}$ and $0.1 \mathrm{~N} / \mathrm{m}^{3}$, respectively. In the model, the horizontal interfaces were assumed to have perfect contact, whereas the vertical interfaces (between the trench and the surrounding soil and the original pavement) had weak contact, which is the most unfavourable hypothesis.

The horizontal interfaces were assumed to have perfect contact. The vertical interfaces between the trench and the surrounding soil were simulated as having weak contact. Conversely, the vertical interfaces between the asphalt pavement and the expansive concrete were assumed to have perfect contact. This assumption accounted for the fact that the
TABLE 1. Properties of the pavement types, the soil and the backfill

\begin{tabular}{lcc}
\hline Material & $\begin{array}{c}\text { Poisson } \\
\text { coefficient (-) }\end{array}$ & $\begin{array}{c}\text { Modulus of } \\
\text { elasticity (MPa) }\end{array}$ \\
\hline Asphalt & 0.32 & 3000 \\
Concrete & 0.20 & 20000 \\
Backfill & 0.35 & $10-50-100-200-300$ \\
Top sub-base & 0.30 & $300-500-1000$ \\
Bottom sub-base & 0.30 & $150-300-600$ \\
Surrounding soil & 0.30 & $75-150-300$ \\
\hline
\end{tabular}

stiffness of the interface between the asphalt pavement and the expansive concrete tended to be considerably higher than for the other vertical interfaces. Because the interface would bear the biggest portion of the load, it would be the most likely to fail. Such an assumption was on the safe side since in real scenarios part of the load may also be transmitted through the interface between the trench and the surrounding soils. This reduces the trench's dependence on the soil type and soil humidity, which is a clear advantage of the new trench solution proposed here.

Regarding the other materials, linear elastic behaviour was assumed since high levels of stress, which entail a non-linear analysis, were not expected. The stress level in each model was verified to assure that the material remained in the elastic regime. In this context, two main parameters defined the materials: the modulus of elasticity and the Poisson coefficient. The properties of the asphalt and concrete pavement are presented in Table 1. The properties of the granular backfill and the surrounding soil were considered variables of the parametric study, and their values are described in subsequent sections.

The traffic load applied in the model was defined according to Spanish traffic regulations, which specify the maximum load allowed per tyre. Considering the critical case of double tyres, the specified maximum 
load per axis is $115 \mathrm{kN}$. To be on the safe side, the value of $120 \mathrm{kN}$ was used in all simulations. To simplify the model and reduce the number of elements, the load was concentrated on the generatrix of the tyre instead of the tyre footprint. This assumption represents a more critical situation that should also be on the safe side. Force was applied in 10 load steps equal to $12 \mathrm{kN}$. Both load profiles depicted in Fig. 3 were simulated. Once the full force was applied, the shear and the tensile stresses of the interface were assessed and the required confinement to avoid failure was calculated using Eq. [1] and Eq. [4] for the tensile and shear failures.

The friction coefficient was calculated assuming a friction angle of $45^{\circ}$. This value assumes that a rough asphalt surface is left after the trencher excavates the original asphalt pavement, leading to an increase in friction at the interface. The cohesion value used in the calculations was $0.5 \mathrm{MPa}$.

\subsection{Definition of the variables}

The variables considered in the numerical simulation were the properties of the backfill and of the surrounding soil. Again, the materials are defined by the Poisson coefficient and the modulus of elasticity. However, given that the Poisson coefficient did not have a significant influence on behaviour, it remained constant during the parametric study. Therefore, the study's variable was the modulus of elasticity, which varied with the nature and the degree of soil compaction and the backfill. Table 1 summarizes the properties of the materials, including the values considered in the parametric study. The graded aggregate sub-base was divided into two layers (as shown in Fig. 4), each with different properties. Based on the modulus of elasticity values presented in Table 1, the parametric analysis of 15 different combinations of soils was carried out, assuming that the upper layers were always less flexible than the bottom layers.

\subsection{Parametric study}

Fig. 5 presents the minimum values of the confinement stress $\left(\sigma_{e}\right)$ required to avoid tensile failure for the different modulus of elasticity values considered. The values on the horizontal axis correspond to the modulus of elasticity of the surrounding soil $(75,150$ and $300 \mathrm{MPa})$. Below them are the modulus of elasticity values for the bottom surface layer or sub-base $(150,300$ and $600 \mathrm{MPa})$, the top surface layer or sub-base $(300,500$ and $1000 \mathrm{MPa})$, and the backfill $(10,50,100,200$ and $300 \mathrm{MPa})$. Each grey column represents the confinement stress, or internal stress, associated with the trio of values for the surrounding soil and sub-bases given for each column and thus represents the minimum confinement $\sigma_{e}$ required. The results in Fig. 5a and Fig. 5b reveal that $\sigma_{e}$ decreases as the modulus of elasticity for the sub-base decrease and the modulus of elasticity of the surrounding soil increases. This tendency may be attributed to the fact that when the stiffness of the soil increases, the possible bending forces created by the traffic loads decrease and, as a result, the tension at the interface also decreases.

In Fig. 5a, the values of $\sigma_{e}$ are not significantly affected by variations in the modulus of elasticity for the backfill material. For example, for a modulus of $10 \mathrm{MPa}$ the values of $\sigma_{e}$ for all three combinations of the rest of the materials are similar to those of a modulus of the backfill of $200 \mathrm{MPa}$. However, in the case of Fig. 5b the difference is bigger. Such an outcome reveals that the influence of the degree of compaction on the tensile failure depends on the width of the trench. For narrower trenches, failure is most affected by the stiffness of the surrounding soil, whereas for wider trenches compaction has larger repercussions. From the results, it may be concluded that the values of $\sigma_{e}$ required to avoid tensile failure range between $0.21 \mathrm{MPa}$ and $0.55 \mathrm{MPa}$ for trenches that are $0.15 \mathrm{~m}$ wide and between $0.24 \mathrm{MPa}$ and $0.55 \mathrm{MPa}$ for trenches of $0.25 \mathrm{~m}$ wide.

The results in Fig. 6 for shear failure show a different tendency from the outcome described for tension failure. In this case, $\sigma_{e}$ increases with the modulus of elasticity for the sub-bases and the surrounding soil, and the influence of the backfill is bigger for both trenches $(0.15 \mathrm{~m}$ and $0.25 \mathrm{~m}$ wide).

Such behaviour may be understood by considering that in soils with higher stiffness, the displacements are smaller and distributed within a shorter length of the trench. Consequently, the tangential stresses are concentrated in a smaller area and higher values of $\sigma_{e}$ are required in order to bear the loads. Conversely, the displacements in flexible soils are larger and occur along a bigger length of the trench, leading to smaller tensions. Based on the previous analysis, it follows that the degree of compaction of the backfill has a noticeable influence on the results. The minimum values of $\sigma_{e}$ needed to avoid shear failure range between $0.28 \mathrm{MPa}$ and $0.75 \mathrm{MPa}$ for the $0.15 \mathrm{~m}$ wide trench (see Fig. 6a) and between $0.30 \mathrm{MPa}$ and $0.87 \mathrm{MPa}$ for the $0.25 \mathrm{~m}$ wide trench (see Fig. 6b).

The parametric study shows that the most critical failure mode is shear, since higher internal stress values for the expansive concrete are required in this case. Moreover, a range of values for $\sigma_{e}$ may be defined in order to prevent any type of failure in the trench. In terms of the displacements generated by the traffic loads, the FE model indicates that the highest displacement in the top surface of the trench occurs for the most flexible soil, and this displacement is lower than $1.0 \mathrm{~mm}$. This value may be considered negligible since it does not affect the comfort of drivers, pedestrians or the functionality of the trench. Once the ranges of confinements required 

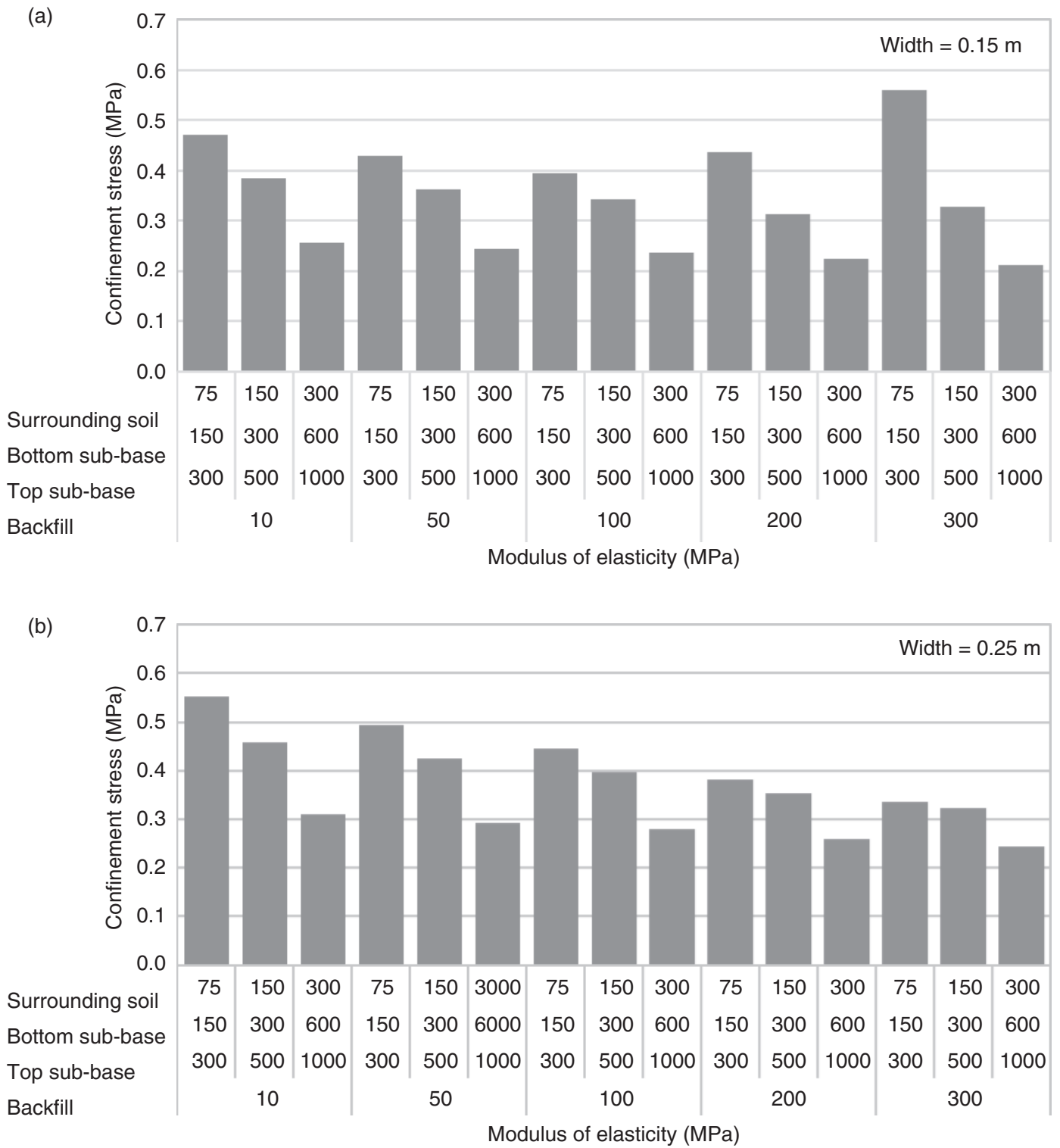

FIGURE 5. Minimum internal tension of the expansive concrete to avoid tensile failure for a trench: (a) $0.15 \mathrm{~m}$ wide and (b) $0.25 \mathrm{~m}$ wide.

to assure stability are determined, it is necessary to verify whether the material is capable of generating such confinement.

\section{EXPERIMENTAL STUDY OF THE EXPANSION OF CONCRETE}

\subsection{Background}

In ordinary Portland cement, the hydration process is governed by the reactions between the main constituents of clinker $\left(\mathrm{C}_{3} \mathrm{~S}, \mathrm{C}_{2} \mathrm{~S}, \mathrm{C}_{3} \mathrm{~A}\right.$ and $\mathrm{C}_{4} \mathrm{AF}$ ), gypsum and water. Most of the hydration reactions of the clinker components are exothermic. As occurs in the case of clinker, the hydration of calcium oxide $(\mathrm{CaO})$ releases heat, approximately $155 \mathrm{Kcal} / \mathrm{kgCaO}$ (14). However, this reaction is not only highly exothermic but also expansive. The increment in volume due to the transformation of $\mathrm{CaO}$ is twice the initial volume of the reactants.

The increase in temperature caused by adding $\mathrm{CaO}$ to the concrete mix might accelerate the speed of the chemical reactions. This depends on the size of the particle or the presence of agglomerates since these may vary the speed of the $\mathrm{CaO}$ hydration and thus the temperature. Accordingly, bigger particle sizes may lead to lower hydration temperature values and smaller $\mathrm{CaO}$ particles could accelerate the reaction. If $\mathrm{CaO}$ particles have a specific surface that is similar to cement particles 

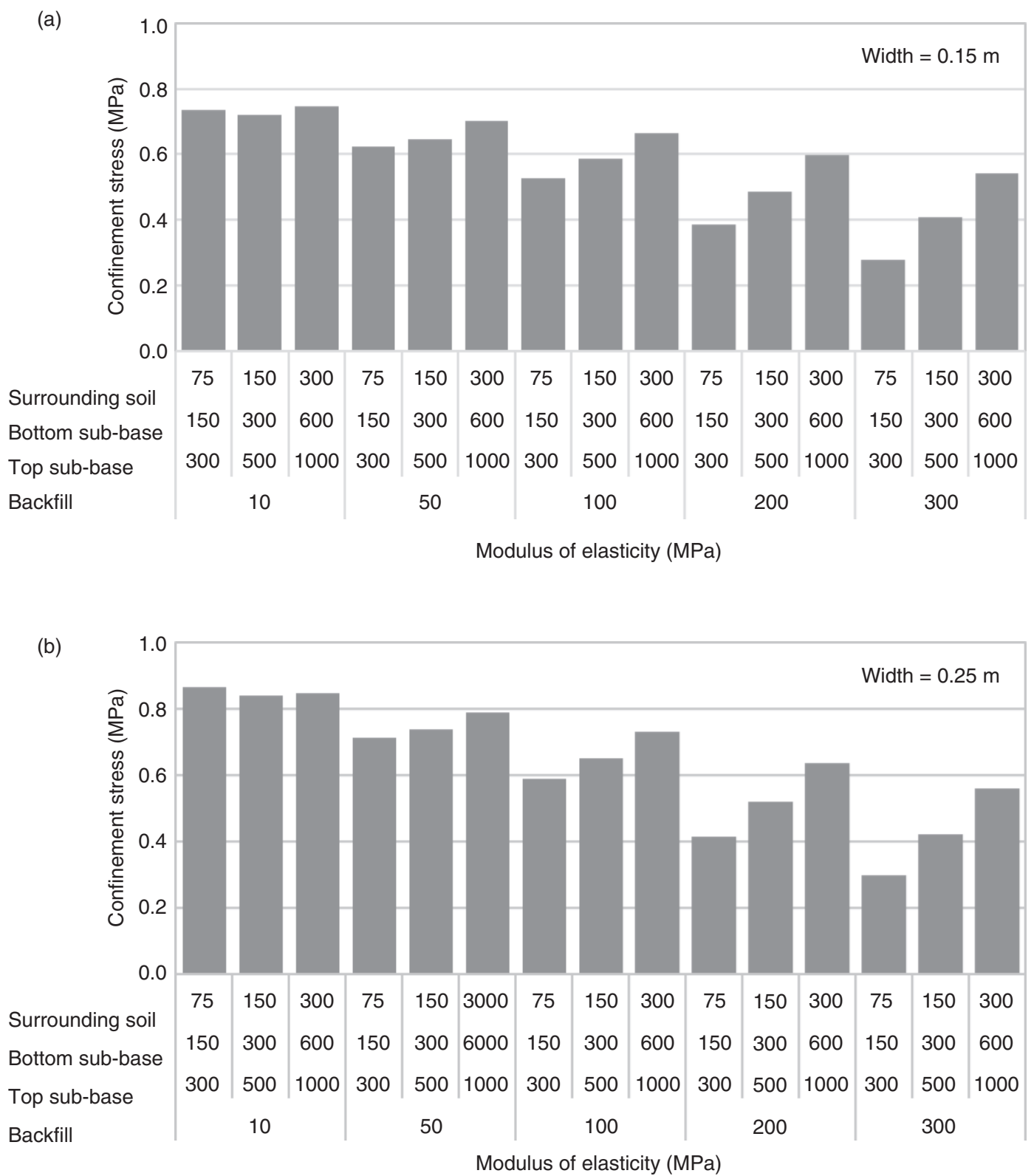

FIgURE 6. Minimum internal tension of the expansive concrete to avoid shear failure: (a) $0.15 \mathrm{~m}$ wide and (b) $0.25 \mathrm{~m}$ wide.

or are similar to them in terms of size, they would both compete to combine with the water. In such cases, the mixing order of the concrete components should be modified in order to improve the material's response to shrinkage.

\subsection{Testing method for evaluating the expansion in concrete}

As noted in the previous section, the main effect of adding $\mathrm{CaO}$ to concrete mixes is a volumetric expansion of the material. However, the numerical simulation run to determine the requirements for the expansive concrete that would ensure an acceptable response from the eco-trench does not provide a value for volume increment. In fact, the expansive concrete layer is under confined conditions that restrain expansion, and therefore the model yields a range of internal stresses in the concrete.

This situation requires a test method that is capable of measuring the internal stresses generated in the concrete due to the presence of $\mathrm{CaO}$ under confined conditions. The ASTM International includes two standards with test methods for evaluating the restrained expansion of expansive cement mortar (15) and concrete (16). Nevertheless, these methods do not evaluate the internal stresses and they restrict the measurement of the expansion to 
(a)

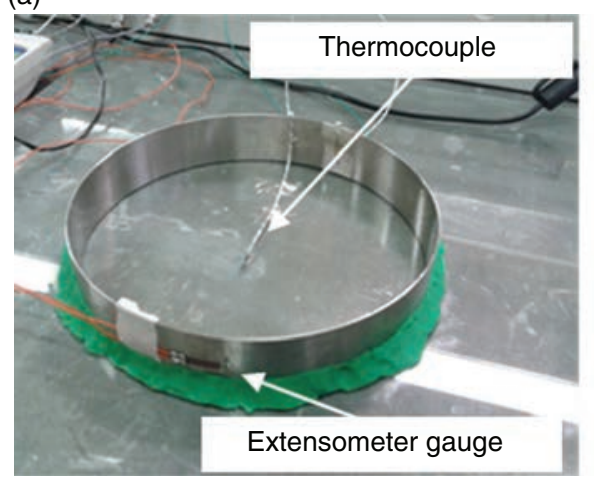

(b)

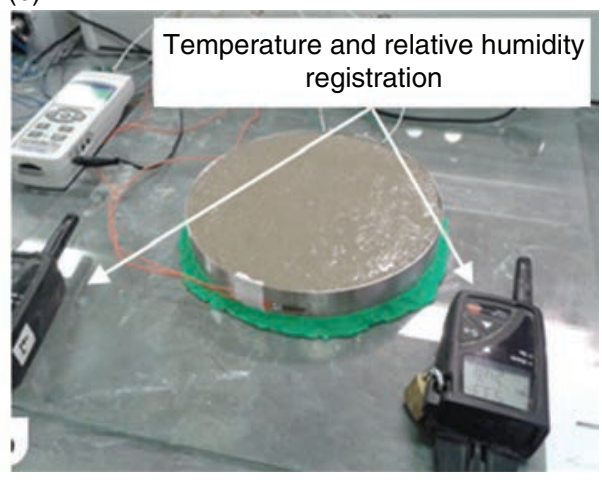

FIGURE 7. (a) Ring and instrumentation, (b) ongoing test with instrumentation.

one dimension. In fact, to the best of the authors' knowledge, there are no methods given in standards or in the literature that are dedicated specifically to the confinement stresses of concrete with $\mathrm{CaO}$.

Considering this, a new testing method was developed at the Universitat Politècnica de Catalunya to evaluate the confinement stress that mortar or concrete experiences at early ages due to the addition of an expansive admixture. This method uses a metallic ring that has a $110-\mathrm{mm}$ radius $(R)$, is $1 \mathrm{~mm}$ thick (e) and $40 \mathrm{~mm}$ tall and is instrumented with extensometer gauges attached to the ring in the perimeter direction in order to measure its deformation (see Fig. 7a). Given that the properties of the ring are known (see Table 2), it was possible to determine the stress generated by the confined concrete expansion over time.

Besides the deformation of the ring $\left(\varepsilon_{s}\right)$, the temperatures for the mix, the environment and the ring were also registered in order to assess their influence on the deformation (see Fig. 7b). The ring was kept in a curing room at $20^{\circ} \mathrm{C}$ and $100 \%$ relative humidity. The confinement stresses were calculated over time in the test using Eq. [5]. In this equation, $E_{s}$ is the modulus of elasticity of the ring's steel, $R$ is the ring's radius, $e$ is the ring's thickness, $\Delta t$ is the variation of the temperature the ring has experienced since the beginning of the test, and $\alpha_{s}$ is the thermal expansion coefficient.

$$
\sigma_{e}=\frac{E_{s} \cdot R}{e}\left(\varepsilon_{s}-\Delta t \cdot \alpha_{s}\right)
$$

\subsection{Description of the materials and the mixes}

\subsubsection{Properties of the $\mathrm{CaO}$}

Three types of $\mathrm{CaO}$ were used in the experimental program to evaluate the confined stress. Prior to undertaking the experimental program, several tests were performed on the three types of $\mathrm{CaO}$ in order to determine their density, their specific weight and
TABLe 2. Properties of the metallic ring

\begin{tabular}{lc}
\hline Properties & Value \\
\hline Modulus of elasticity $(\mathrm{GPa})$ & 200 \\
Thermal expansion coefficient $\left({ }^{\circ} \mathrm{C}^{-1}\right)$ & $1.20 \cdot 10^{-5}$ \\
Poisson coefficient $(-)$ & 0.28 \\
Diameter $(\mathrm{mm})$ & 220 \\
Thickness $(\mathrm{mm})$ & 1.0 \\
\hline
\end{tabular}

TABLE 3. Properties and composition of the $\mathrm{CaO}$

\begin{tabular}{llccc}
\hline & & \multicolumn{3}{c}{ Type of CaO } \\
\cline { 2 - 5 } Properties and composition & MCN & MCR & MCL \\
\hline $\begin{array}{llcc}\text { Physical } \\
\text { properties }\end{array}$ & Density $\left(\mathrm{g} / \mathrm{cm}^{3}\right)$ & 2.81 & 3.04 & 3.02 \\
& Specific surface $\left(\mathrm{m}^{2} / \mathrm{g}\right)$ & 2.77 & 2.12 & 2.55 \\
$\begin{array}{l}\text { Reactivity } \\
\text { potential }\end{array}$ & Time to $\mathrm{pH}=12(\mathrm{~min})$. & 21.5 & 12.0 & 29.5 \\
\hline
\end{tabular}

their potential reactivity. For the purpose of this study the three types will be designated as MCN, MCR and MCL. The density and the specific weight were assessed according to the methodology described by Formosa (17). The potential reactivity of $\mathrm{CaO}$ was evaluated by means of the time required to reach a $\mathrm{pH}$ equal to 12 . Table 3 presents the results obtained from these tests.

The results in Table 3 indicate that MCR and MCL present similar density values, while the density of $\mathrm{MCN}$ is slightly lower, namely $7.6 \%$ lower. In terms of the specific surface, the lowest value corresponds to MCR and the highest corresponds to $\mathrm{MCN}$, which is $30.7 \%$ higher. The biggest differences among the types of $\mathrm{CaO}$ are observed in the reactivity potential. The $\mathrm{CaO}$ with the highest reactivity potential is $\mathrm{MCR}$, since it reaches a $\mathrm{pH}$ of 12 in the shortest amount of time. MCN and MCL present significantly lower reactivity potentials relative to MCR. MCN requires almost twice as long to reach $\mathrm{pH}=12$, and $\mathrm{MCL}$ takes 2.5 times longer than MCR. 


\subsubsection{Making the mortar mixes}

The expansion generated by the addition of $\mathrm{CaO}$ was evaluated in mortars instead of concrete for two main reasons. Firstly, the production of mortar in the laboratory is simpler than in the case of concrete, with the additional advantage of saving material. Secondly, the lack of coarse aggregate in the mix does not affect the results since the expansive admixtures or $\mathrm{CaO}$ react with water and not with the coarse aggregates, which may be considered inert.

Several mortar mixes were made in the experimental program: three of them contained different types of $\mathrm{CaO}$ and another was plain mortar without $\mathrm{CaO}$, which was used as a reference. The composition was the same for all mixes, with a cement-sand ratio of $1: 3$ by weight. Portland cement CEM I 42.5R and normalized silica sand with a size of $0-2 \mathrm{~mm}$, as established under standard UNE-EN 196-1:2005 (18), were used in the mix. The water to cement ratio (w/c) was 0.45 in order to attain a consistency that was fluid enough to allow the ring to be filled but was also consistent enough to prevent the loss of material through the joints. Furthermore, $1 \%$ by cement weight of a plasticizer admixture was added to the mix. The content of $\mathrm{CaO}$ is $7 \%$ by weight of cement, according to the maximum value recommended by the manufacturer.

The production of the mortar started with mixing the water, cement and superplasticizer for $1 \mathrm{~min}$ ute at $28.5 \mathrm{~Hz}$. Afterwards, the $\mathrm{CaO}$ was added and the components were mixed for another 30 seconds. Then, the mixer was stopped for 30 seconds in order to scrape the material off the mixer walls. The mixer was turned on again at the same frequency and the silica sand was added and mixed with the rest of the components for 1 minute. At this point, the mixer was stopped once more for 1.5 minutes to scrape the walls of the mixer. Finally, the mixer was turned on again and the components were mixed for 1 minute at $52.0 \mathrm{~Hz}$. The complete mixing procedure took less than 6 minutes. After the mortar was made, it was poured inside the test ring and the setup was prepared. Preparing the test rign and the setup took less than 10 minutes.

\subsection{Analysis of the results}

Fig. 8 shows the $\sigma_{e}$ values obtained for the mortars via the proposed testing method. The curves indicate that the highest stresses were generated in the MCR mortar, followed by the MCN and MCL mortars. Furthermore, for the early stages of the setting (up to 8 or 12 hours, depending on the mix), no stresses were measured. At this moment, the mortars were still in a plastic state, and the potential expansion was not converted into stresses due to the low or null stiffness of the material. After setting, the expansions resulted in the stresses shown in Fig. 8. In this regard, the mortar that required the longest amount of time to develop the stresses was the one containing MCL.

The kinetics of the reaction may be analysed through the slope of the curves, which reveal that the rate at which the stresses developed during the first 24 hours was not the same for all mixes. In fact, the mix containing MCR showed a faster reaction than the mixes with $\mathrm{MCN}$ and MCL.

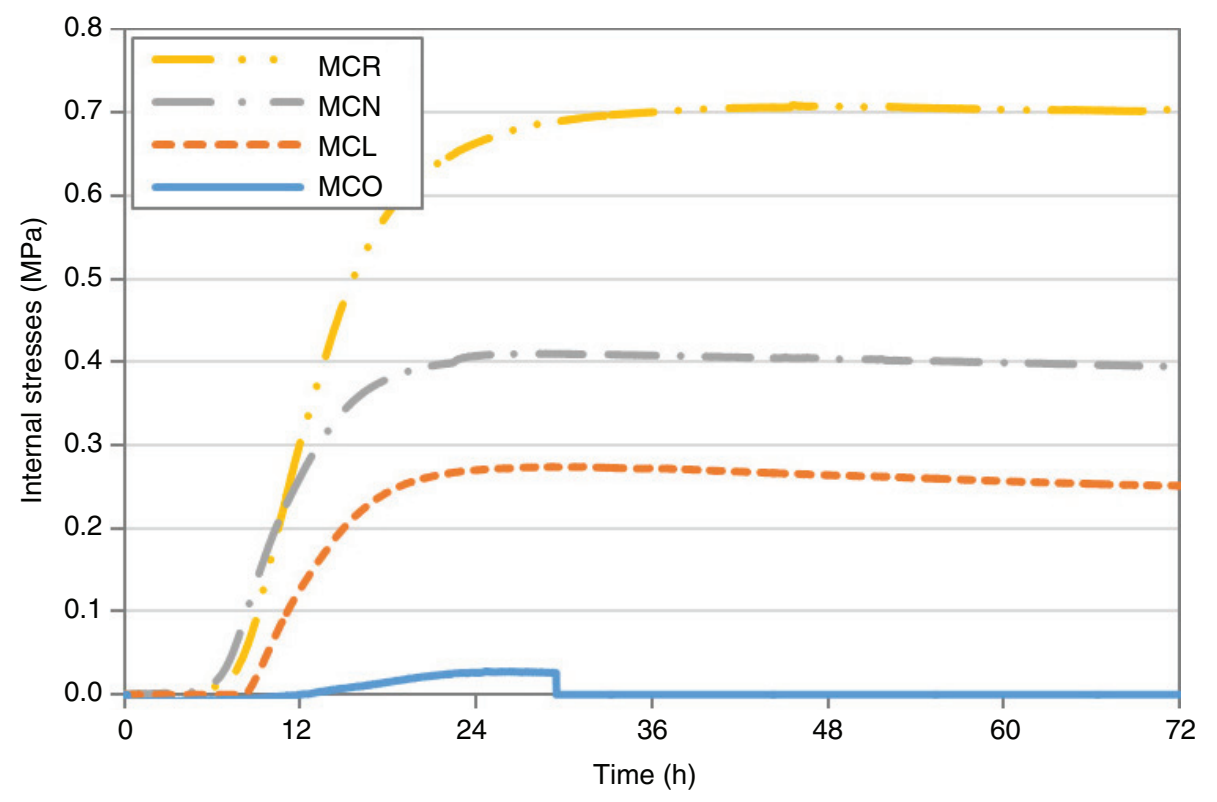

FIGURE 8. Evolution of the internal stresses with time. 
(a)

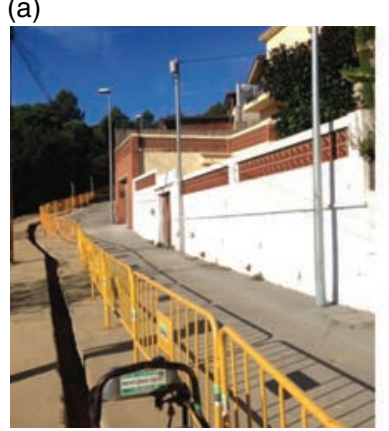

(b)

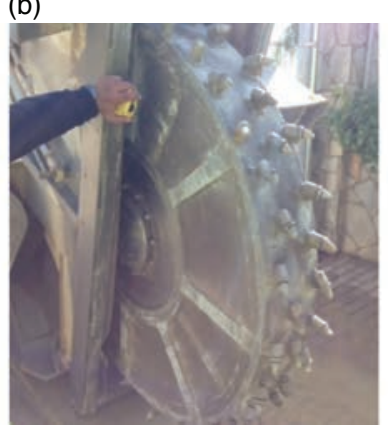

(c)

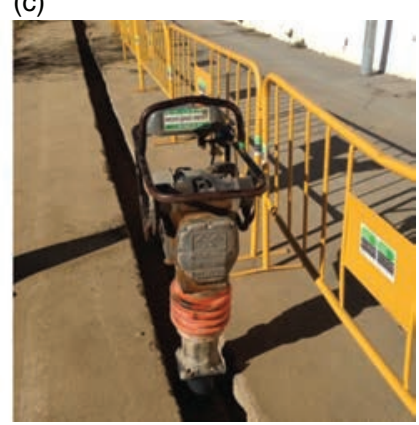

FIGURE 9. (a) General view of the site, (b) disk of the trencher and (c) compactor.

In terms of the maximum confinement stress registered, the mortars with $\mathrm{CaO}$ reached values between 0.2 $\mathrm{MPa}$ and $0.7 \mathrm{MPa}$. The FE model indicated that the range of minimum stress values required to avoid shear failure go from $0.30 \mathrm{MPa}$ to $0.87 \mathrm{MPa}$, which is the most restrictive condition. Therefore, the value of 0.9 MPa for internal stress may be established as a reference value for avoiding failure and transmitting stresses to the adjacent ground.

The experimental results confirmed that including $\mathrm{CaO}$ in the mortar mixes makes it possible to generate the confinement required for eco-trenches. Depending on the type of $\mathrm{CaO}$ used in the concrete mix and the environmental conditions, the $\mathrm{CaO}$ content should be increased slightly to ensure the minimum value of $0.9 \mathrm{MPa}$.

\section{PILOT EXPERIENCE}

The solution proposed for the eco-trench was applied at a work-site of the city of Barcelona, Spain (see Fig. 9a), in November of 2014. The trench selected for the pilot experience was $25 \mathrm{~cm}$ wide (the diameter of the pipe was $90 \mathrm{~mm}$ ) and $80 \mathrm{~cm}$ deep. The trench was excavated by a trencher with a 25-cm disk (see Fig. 9b). The excavated material was crushed and placed alongside the trench. The material was then sieved manually, and debris or other big particles from the original asphalt pavement were removed. The rest of the material from the bottom layers was of a size that is suitable for use as backfill for the trench; this material was placed back in the trench. The granular backfill was compacted using a manual compactor that was compatible with the trench's 25-cm width (see Fig. 9c) in order to assure the trench was properly filled.

When the layers of granular backfill were ready, the expansive concrete layer was applied. In this case, two different thicknesses $(15 \mathrm{~cm}$ and $20 \mathrm{~cm})$ were used in the trench in order to assess their behaviour over time. The concrete mix employed is detailed in Table 4 . The w/c ratio was adapted from the one used
TABLE 4. Concrete mix used in the pilot experience

\begin{tabular}{llc}
\hline Materials & \multicolumn{1}{c}{ Characteristics } & Content $\left(\mathbf{k g} / \mathbf{m}^{\mathbf{3}}\right)$ \\
\hline Cement & CEM II/A-L 42,5R & 196.0 \\
Gravel 10/20 & - & 790.0 \\
Gravel 4/10 & & 109.0 \\
Sand 0/4 & - & 1085.0 \\
Water & - & 155.0 \\
Additive & Pozzolith 475 N & 1.37 \\
& Glenium SKY 866 & 0.59 \\
CaO admixture & Link-EVR (MCN) & 25.0 \\
\hline
\end{tabular}

in the laboratory because the aggregates employed in the pilot experience are different. For this reason, the w/c ratio is 0.79 . Given that the $\mathrm{CaO}$ used in the MCN mixture yielded better control of the reaction kinetics in the laboratory setting (see Table 3), MCN was the type of $\mathrm{CaO}$ added to the concrete mix for the pilot experience. The $\mathrm{CaO}$ content was increased up to $12 \%$ by weight of cement in order to ensure that the required level of internal stress as indicated in Fig. 8 was attained.

The truck poured the concrete directly into the trench, thus speeding up execution (see Fig. 10a). The consistency of the concrete was an important factor in favouring the spread of the material along the trench (see Fig. 10b). The average compressive strength of the expansive concrete, following EN12390-3:2009 (19), was 18.6 MPa, which was in line with what was expected for the concrete mix.

Fig. 10c shows the finished trench one month later, with no signs of shrinkage in the walls of the trench. Moreover, ten months after construction, no differences in behaviour had been reported for the stretches with expansive concrete layers of $15 \mathrm{~cm}$ and $20 \mathrm{~cm}$. In terms of aesthetic appearance, the trench's colouring was similar to the original pavement. However, if a darker concrete were required in order to match the original asphalt pavement, pigments may be used in the concrete mix. 
(a)

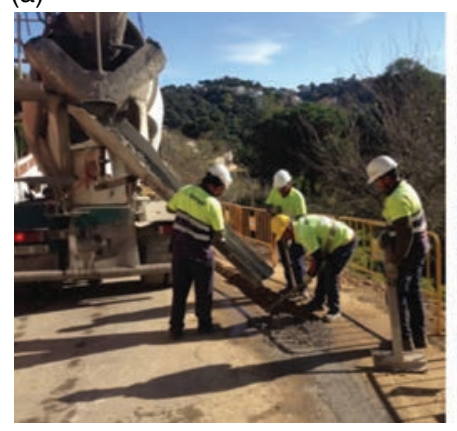

(b)

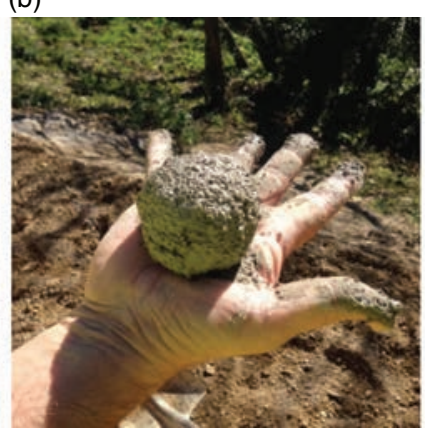

(c)

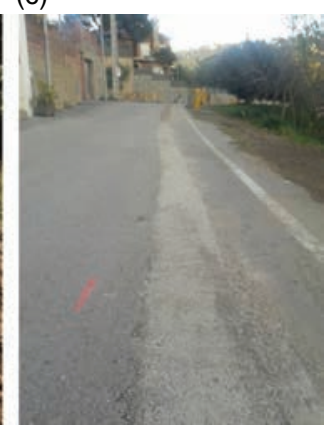

FIGURE 10. (a) Pouring of the concrete, (b) consistency verification and (c) finished trench.

\section{CONCLUSIONS}

The present study proposes a novel eco-trench solution for underground utility infrastructure needs, such as gas distribution, which consists of re-using the trench arisings as the main backfill material and finishing the trench with a top layer of expansive concrete. The numerical model and the experimental program indicate that it is a feasible solution with significant advantages in terms of structural behaviour, logistics and sustainability. The following conclusions may be drawn from the results of the study.

- The numerical simulation revealed that the critical parameter in determining the eco-trench's behaviour is shear strength at the interface. Therefore, the most restrictive failure mechanism is shear.

- The parametric study indicated that, for the dimensions and the material properties simulated, the expansive concrete in the top layer must generate a sustained confinement that falls between $0.30 \mathrm{MPa}$ and $0.87 \mathrm{MPa}$ in order to avoid tensile or shear failure caused by traffic loads and to ensure the transmission of stresses to the surrounding soil.

- The above range of internal stresses ensures that displacement at the top of the trench is negligible, and the comfort or the functionality of the pavement is not affected.

- The proposed experimental test is capable of assessing the level of confinement generated by adding $\mathrm{CaO}$. According to the results of the test, including such an admixture may provide sufficient confinement for preventing the failure of the interface.

- The pilot experience was satisfactory in terms of execution and the trench's mechanical performance. In this case, the content of calcium oxide was increased to $12 \%$ by weight of cement.

\section{ACKNOWLEDGEMENTS}

The authors would like to acknowledge Gas Natural SDG, S.A. for their collaboration and support of this project. The authors also express their gratitude to Cales de Pachs S.A., PROMSA and Nubiola Pigmentos S.L. for their contribution to the experimental studies. The authors thank the support provided by the Spanish Ministry of Economy and Competitiveness in the scope of the project with reference number IPT-2012-0313-370000. The second and third author acknowledge the PDJ and FI grants provided by the Departament d'Universitats, Recerca i Societat de la Informació of the Generalitat de Catalunya.

\section{REFERENCES}

1. Etxebarria, M.; Ainchil, J.; Pérez, M.E.; González, A. (2013). Use of recycled fine aggregates for Control Low Strength Materials (CLSMs) production. Constr. Build. Mater. 44, 142-148. https://doi.org/10.1016/j. conbuildmat.2013.02.059

2. Blanco, A.; Pujadas, P.; Cavalaro, S.H.P.; Aguado, A. (2014). Methodology for the design of controlled lowstrength materials. Application to the backfill of narrow trenches, Constr. Build. Mater. 72, 23-30. https://doi. org/10.1016/j.conbuildmat.2014.09.008

3. Pujadas, P.; Blanco, A.; Cavalaro, S.; Aguado, A. (2015). Performance-Based Procedure for the Definition of Controlled Low-Strength Mixtures. J. Mater. Civil Eng. 10.1061/(ASCE)MT.1943-5533.0001283, 06015003. https:// doi.org/10.1061/(asce)mt.1943-5533.0001283

4. Petit-Boix, A.; Roigé, N.; de la Fuente, A.; Pujadas, P.; Gabarrell, X.; Rieradevall, J.; Josa, A. (2016). Integrated Structural Analysis and Life Cycle Assessment of Equivalent Trench-Pipe Systems for Sewerage. Water Resour. Manag. 30 [3], 1117-1130. https://doi.org/10.1007/ s11269-015-1214-5

5. WRAP (Waste \& Resources Action Program). (2005). Identifying opportunities for recycling of excavated spoil from utility works within local authority areas, and promoting the use of recycled materials through good practice in procurement. Banbury, U.K.

6. WRAP (Waste \& Resources Action Program). (2007). Recycled and stabilised materials in trench reinstatement, WAS005-002: Final Report, Banbury, U.K.

7. Chatterji, S. (1995). Mechanism of expansion of concrete due to the presence of dead-burnt $\mathrm{CaO}$ 
and MgO. Cem. Concr. Res. 25, 51-56. https://doi. org/10.1016/0008-8846(94)00111-B

8. Min, D.; Dongwen, H.; Xianghui, L.; Mingshu, T. (1995). Mechanism of expansion in hardened cement pastes with hard-burnt free lime. Cem. Concr. Res. 25 [2], 440-448. https://doi.org/10.1016/0008-8846(95)00030-5

9. Maltese, C.; Pistolesi, C.; Lolli, A.; Bravo, A.; Cerulli, T.; Salvioni, D. (2005). Combined effect of expansive and shrinkage reducing admixtures to obtain stable and durable mortars. Cem. Concr. Res. 35[12], 2244-2251. https://doi. org/10.1016/j.cemconres.2004.11.021

10. Carballosa, P.; Calvo, J.L.G.; Revuelta, D.; Sanchez, J.J.; Gutierrez, JP. (2015). Influence of cement and expansive additive types in the performance of self-stressing and self-compacting concretes for structural elements. Constr. Build. Mater. 93, 223-229. https://doi.org/10.1016/j. conbuildmat.2015.05.113

11. Pade, C.; Guimaraes, M. (2007). The $\mathrm{CO}_{2}$ uptake of concrete in a 100-year perspective. Cem. Concr. Res. 37 [9],1348-1356. https://doi.org/10.1016/j.cemconres.2007.06.009

12. Yang, K-H.; Seo, E-A.; Tae, S-H. (2014). Carbonation and $\mathrm{CO}_{2}$ uptake of concrete. Environmental Impact Assessment Review. 46, 43-52. https://doi.org/10.1016/j.eiar.2014.01.004
13. TNO Diana BV. (2008). Diana User's Manual, (http://www. tnodiana.com/)

14. Ecole d'Avignon. (2005). Techniques et pratique de la chaux. Eyrolles, Ed. $2^{\text {nd }}$ edition, Paris, France.

15. ASTM (American Society for Testing and Materials). (1995). C806-95 Standard Test Method for Restrained Expansion of Expansive Cement Mortar 1, West Conshohocken, PA.

16. ASTM (American Society for Testing and Materials). (2009). C878/C878M-09 Standard Test Method for Restrained Expansion of Shrinkage-Compensating Concrete, West Conshohocken, PA.

17. Formosa, J. (2012). Formulaciones de nuevos morteros y cementos especiales basadas en subproductos de magnesio. Doctoral Thesis, Universitat de Barcelona, Barcelona, (in Spanish).

18. AENOR (Spanish Association for Standardization and Certification). (2005). UNE-EN 196-1:2005. Methods of testing cement - Part 1: Determination of strength, Madrid, Spain.

19. CEN (European Committee for Standardization). (2009). EN12390-3:2009. Part 3: Compressive strength of test specimens, Brussels, Belgium. 